Supporting Information

\title{
Experimental and Computational Investigation of
}

\section{Intra- and Interlayer Space for Enhanced Depth \\ Filtration and Reduced Pressure Drop}

Sanghyun Roh,,$^{\dagger}$ Minwoo Song,,$\dot{+}$ Kyeongeun Lee,,$+\dot{+}$ Kangsoo Park ${ }^{\S}$ and Jooyoun Kim ${ }^{*},+, " \prime$

†Department of Textiles, Merchandising and Fashion Design, Seoul National University, Seoul 08826, Korea

Reliability Assessment Center, FITI Testing \& Research Institute, Seoul 07791, Korea

§R\&D Center, Satrec Initiative Co., Ltd., Daejeon 34054, Korea

"Research Institute of Human Ecology, Seoul National University, Seoul 08826, Korea

Email: jkim256@snu.ac.kr 


\section{Design of filter web morphology}

Table S1 and Figure S1 present the morphological characteristics of electrospun webs resulting from different electrospinning parameters. As PS easily produces various morphologies by simple adjustments of solution concentration and bias voltage, PS was electrospun to form microfibers and microbeads-on-string morphologies. Beads were formed at lower pre-spinning concentrations where the polymer chain entanglement was weak. As the polymer concentration increased, the formation of beads gradually decreased, then the fiber diameter increased, and this tendency was common for both PS and PAN. PAN produced thinner fibers than PS at the controlled process conditions, thus PAN was used to produce nanofiber webs. From Table S1, the process conditions that produce microbeads, microfibers and nanofibers were highlighted and those morphological features were chosen for further investigation.

Table S1. Morphology of electrospun web with varied electrospinning conditions

\begin{tabular}{|c|c|c|c|c|c|c|c|c|c|}
\hline \multirow{4}{*}{ PS } & Conc. (w/v\%) & \multicolumn{2}{|c|}{10} & \multicolumn{2}{|c|}{12} & \multicolumn{2}{|c|}{14} & \multicolumn{2}{|l|}{16} \\
\hline & Applied voltage $(\mathrm{kV})$ & 15 & 20 & 15 & 20 & 15 & 20 & 15 & 20 \\
\hline & Fiber diameter $(\mu \mathrm{m})$ & $\begin{array}{c}0.43 \\
( \pm 0.07)\end{array}$ & $\begin{array}{c}0.46 \\
( \pm 0.06)\end{array}$ & $\begin{array}{c}0.65 \\
( \pm 0.09)\end{array}$ & $\begin{array}{c}0.83 \\
( \pm 0.12)\end{array}$ & $\begin{array}{c}1.05 \\
( \pm 0.15)\end{array}$ & $\begin{array}{c}1.24 \\
( \pm 0.24)\end{array}$ & $\begin{array}{c}2.21 \\
( \pm 0.27)\end{array}$ & $\begin{array}{c}2.92 \\
( \pm 0.29)\end{array}$ \\
\hline & Bead diameter $(\mu \mathrm{m})$ & $\begin{array}{c}5.73 \\
( \pm 3.10) \\
\end{array}$ & $\begin{array}{c}6.87 \\
( \pm 3.53) \\
\end{array}$ & $\begin{array}{c}4.64 \\
( \pm 1.53) \\
\end{array}$ & $\begin{array}{c}5.60 \\
( \pm 1.63) \\
\end{array}$ & $\begin{array}{c}4.45 \\
( \pm 0.76) \\
\end{array}$ & $\begin{array}{c}5.54 \\
( \pm 0.76) \\
\end{array}$ & \multicolumn{2}{|c|}{ Bead-free fiber } \\
\hline \multirow{4}{*}{ PAN } & Conc. (w/v \%) & \multicolumn{2}{|c|}{8} & \multicolumn{2}{|c|}{9} & \multicolumn{2}{|c|}{10} & \multicolumn{2}{|c|}{11} \\
\hline & Applied voltage $(\mathrm{kV})$ & \multicolumn{2}{|c|}{18} & \multicolumn{2}{|c|}{18} & \multicolumn{2}{|c|}{16} & \multicolumn{2}{|c|}{14} \\
\hline & Fiber diameter $(\mu \mathrm{m})$ & \multicolumn{2}{|c|}{$\begin{array}{c}0.24 \\
( \pm 0.03)\end{array}$} & \multicolumn{2}{|c|}{$\begin{array}{c}0.31 \\
( \pm 0.03)\end{array}$} & \multicolumn{2}{|c|}{$\begin{array}{c}0.36 \\
( \pm 0.03)\end{array}$} & \multicolumn{2}{|c|}{$\begin{array}{c}0.40 \\
( \pm 0.04)\end{array}$} \\
\hline & Bead diameter $(\mu \mathrm{m})$ & \multicolumn{2}{|c|}{$\begin{array}{c}4.54 \\
( \pm 2.54)\end{array}$} & \multicolumn{2}{|c|}{$\begin{array}{c}3.61 \\
( \pm 1.36)\end{array}$} & \multicolumn{4}{|c|}{ Bead-free fiber } \\
\hline
\end{tabular}




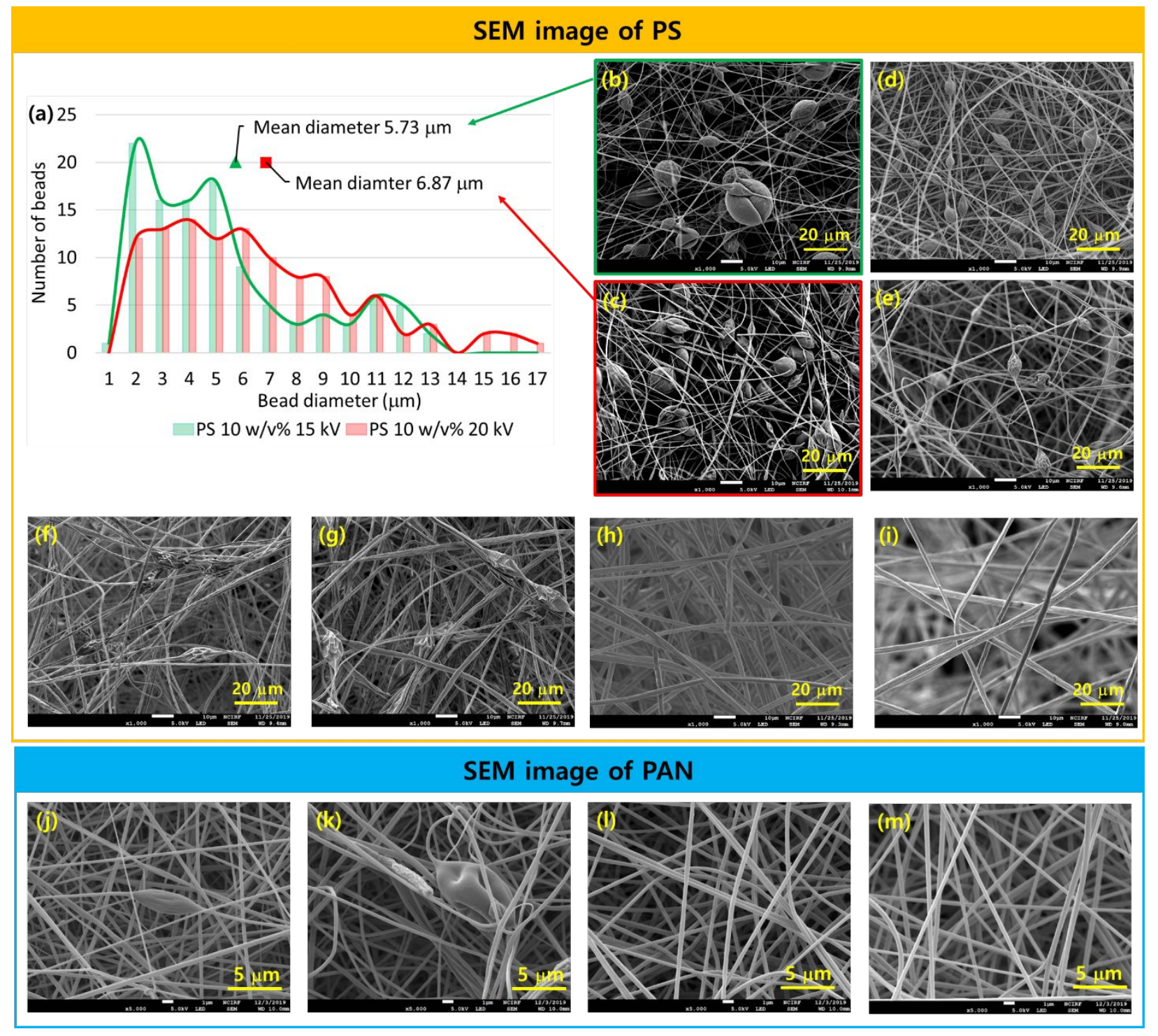

Figure S1. Morphological characterization of electrospun webs. (a) Bead diameter distribution of PS $10 \mathrm{w} / \mathrm{v} \% 15 \mathrm{kV}$ and $20 \mathrm{kV}$, (b m) PS electrospun webs produced by: (b) $10 \mathrm{w} / \mathrm{v} \% 15 \mathrm{kV}$, (c) $10 \mathrm{w} / \mathrm{v} \% 20 \mathrm{kV}$, (d) $12 \mathrm{w} / \mathrm{v} \% 15 \mathrm{kV}$, (e) $12 \mathrm{w} / \mathrm{v} \% 20 \mathrm{kV}$, (f) $14 \mathrm{w} / \mathrm{v} \% 15 \mathrm{kV}$, (g) $14 \mathrm{w} / \mathrm{v} \% 20$ $\mathrm{kV}$, (h) $16 \mathrm{w} / \mathrm{v} \% 15 \mathrm{kV}$, (i) $16 \mathrm{w} / \mathrm{v} \% 20 \mathrm{kV}$. (j m) PAN electrospun webs produced by: (j) $8 \mathrm{w} / \mathrm{v}$ $\% 18 \mathrm{kV}$, (k) $9 \mathrm{w} / \mathrm{v} \% 18 \mathrm{kV}$, (l) $10 \mathrm{w} / \mathrm{v} \% 16 \mathrm{kV}$, (m) $11 \mathrm{w} / \mathrm{v} \% 14 \mathrm{kV}$. 
2. Effect of fibrous morphology on filtration performance and pressure drop

Three different filter webs, n-Fiber, m-Bead, and Fiber-mix in $5 \mathrm{~g} / \mathrm{m}^{2}$, were evaluated for the pressure drop at different face velocities of $4.2,6.25,8.3,10.42,12.5,14.6 \mathrm{~cm} / \mathrm{s}$, respectively. From Figure S2a, the pressure drop of n-Fiber, m-Bead, and Fiber-mix increased linearly as the face velocity increased, following the Darcy's law, which explains the linear relationship between the face velocity and the pressure drop of fluid. ${ }^{1,2}$ The face velocity $(\mathrm{cm} / \mathrm{s})$ is calculated by the flow rate $\left(\mathrm{cm}^{3} / \mathrm{s}\right)$ divided by the surface area $\left(\mathrm{cm}^{2}\right)$. With such relationships, the pressure drops at the varied face velocities in Figure S2a were converted to the pressure drops at the varied surface area, assuming the constant flow rate of 85 LPM (Figure S2b). At the same flow rate, the pressure drop generally decreases as the surface area increases, and the results followed this tendency.

Figure S2(b) represents the results of N-type filter test of the US National Institute for Occupational Safety and Health (NIOSH) 42CFR part 84 protocol. N95 criteria respirator should meet the following requirement: penetration of $\mathrm{NaCl}<5 \%$; inhalation pressure drop $<35 \mathrm{~mm}$ $\mathrm{H}_{2} \mathrm{O}(343 \mathrm{~Pa})$; exhalation pressure drop $<25 \mathrm{~mm} \mathrm{H} \mathrm{H}_{2} \mathrm{O}(245 \mathrm{~Pa})$. The regular size of the flatfold respirator usually has a surface area of about $210 \sim 240 \mathrm{~cm}^{2}$. The pressure drops of all three tested webs of this range surface area were shown to be lower than the required inhalation pressure drop. The Fiber-mix and m-Bead webs showed much lower pressure drop than the required inhalation pressure drop.

Figure S2c shows the penetration of the respective webs, n-Fiber, m-Bead and Fiber-mix. The test was conducted with $40 \mathrm{~cm}^{2}$ at flow rate of 35 LPM and 15 LPM; if the face velocity is to be maintained consistent, such test conditions would correspond to the surface area of $113 \mathrm{~cm}^{2}$ and $227 \mathrm{~cm}^{2}$ tested at the flow rate of 85 LPM. As shown in Figure S2c, the penetrations with $227 \mathrm{~cm}^{2}$ at 85 LPM would be $<0.01,0.43$, and $2.56 \%$ for n-Fiber, m-Bead and Fiber-mix, respectively. 
The results demonstrate that those webs can satisfy the N95 criteria of pressure drop and penetration when applied to filter media with $\sim 227 \mathrm{~cm}^{2}$.
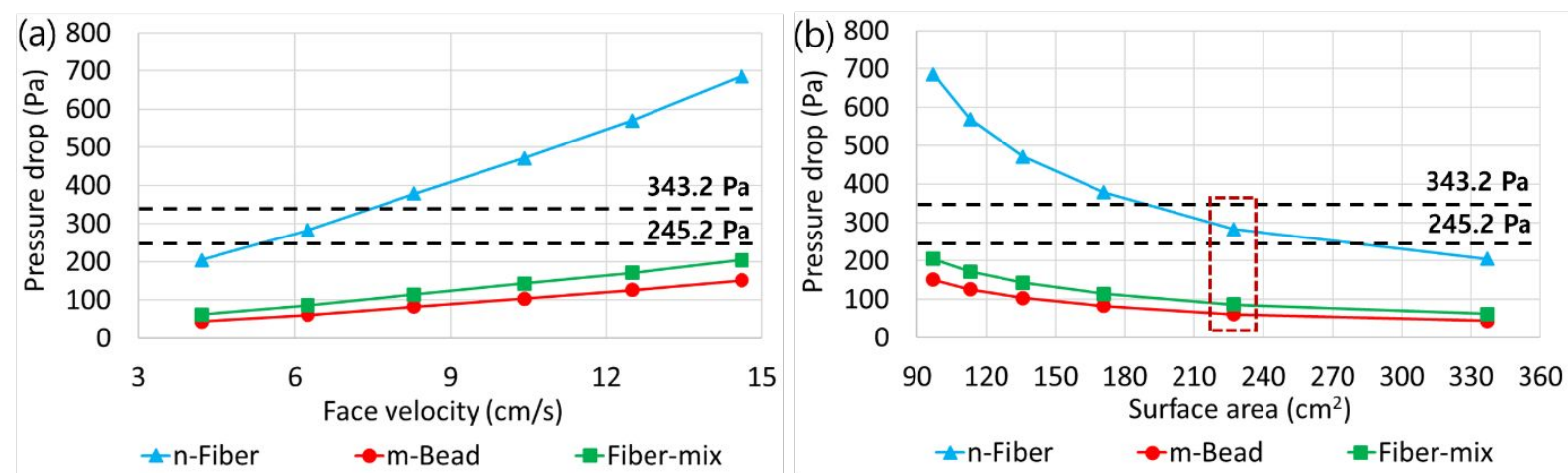

(c) 4

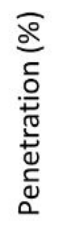
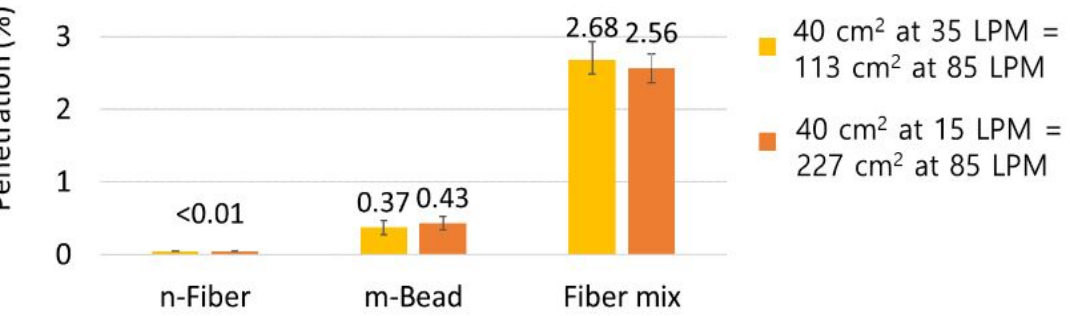

Figure S2. Pressure drop and penetration of n-Fiber, m-Bead, and Fiber-mix webs at different face velocities. (a) Pressure drop tested at different face velocities, (b) pressure drop with different surface area, (c) penetration tested at different flow rate and converted to different surface area.

\section{Modeling and simulation}

A set of simulation work was carried out via commercial solver of GeoDict ${ }^{\circledR}$ software package (Math2Market GmbH, Germany). A regular hexahedral voxel was used (Figure S3), and the grid length was configured to be 10 times smaller than the fiber diameter, so that the grid of the fiber had at least 10 layers. FlowDict ${ }^{\circledR}$ module was used to calculate the initial pressure drop for the constructed filter models. Figure S4 shows the boundary conditions applied for the simulations. Velocity inlet boundary condition was used for the inlet, and pressure outlet was used for the outlet. 
For a reliable prediction, sufficient air layers were applied to the inlets and outlets so as to allow the filter cake development with the considered $\mathrm{NaCl}$ particle size. Periodic boundary condition at peripheral regions was employed to approximate for infinitely long analysis domains.

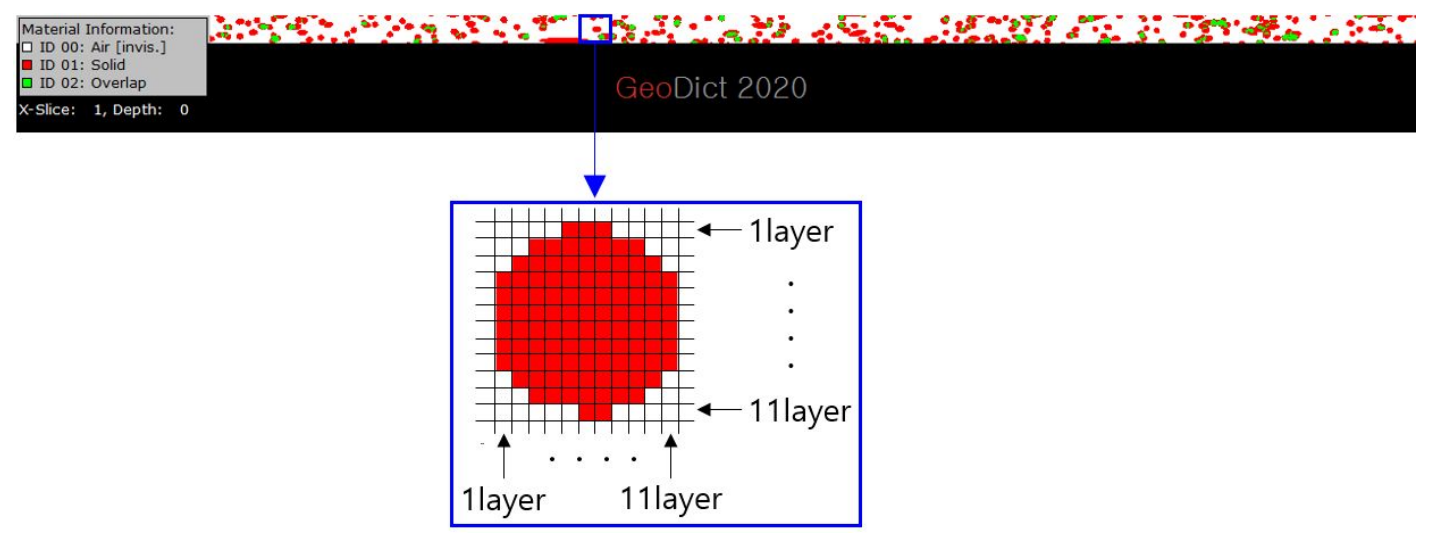

Figure S3. Computational grid used in this study.

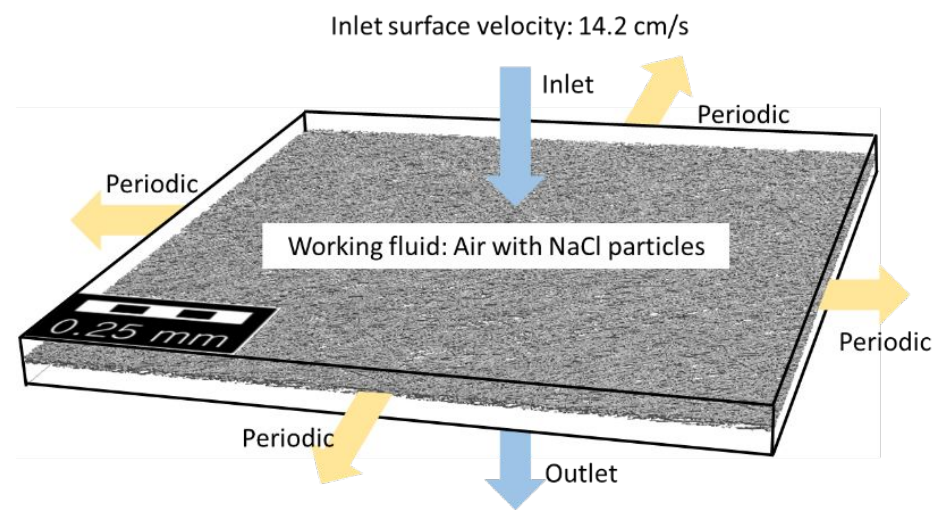

Ambient pressure $=101.325 \mathrm{KPa}$

$<$ Analysis conditions >

Figure S4. Boundary conditions.

The physical characteristics of virtual constructions are shown in Table S2. When calculating the solidity and porosity of the constructed models, the overall porosity of $\mathrm{m}$-fiber single layer (71.0 \%) was greatest, followed by a dual layer with $1.6 \mu \mathrm{m}$ gap (75.1\%), a dual layer with 5.0 $\mu \mathrm{m}$ gap (80.8 \%), and a dual layer with $10.0 \mu \mathrm{m}$ gap (85.7\%). As the gap space was increased by dividing 1 layer into 2 layers, it was found that the overall porosity of the dual layer constructions 
increased considerably. Accordingly, the porosity of the dual layer with $5.0 \mu \mathrm{m}$ gap was about 10 $\%$ higher than a single layer (Table S2).

Table S2. Physical characteristics of modeling constructions

\begin{tabular}{|c|c|c|c|c|}
\hline & $\begin{array}{c}\text { m-Fiber } \\
\text { single layer }\end{array}$ & $\begin{array}{c}\text { 2-layer with } \\
\mathbf{1 . 6} \boldsymbol{\mu m} \text { gap }\end{array}$ & $\begin{array}{c}\text { 2-layer with } \\
\mathbf{5 . 0} \boldsymbol{\mu m} \text { gap }\end{array}$ & $\begin{array}{c}\text { 2-layer with } \\
\mathbf{1 0 . 0} \boldsymbol{\mu m} \text { gap }\end{array}$ \\
\hline Fiber diameter $(\boldsymbol{\mu m})$ & $2.28( \pm 0.37)$ & $2.20( \pm 0.45)$ & $2.20( \pm 0.45)$ & $2.20( \pm 0.45)$ \\
\hline Thickness $(\boldsymbol{\mu m})$ & 10.0 & 11.6 & 15.0 & 20.0 \\
\hline Solidity & 0.29 & 0.249 & 0.192 & 0.143 \\
\hline Porosity (\%) & 71.0 & 75.1 & 80.8 & 85.7 \\
\hline
\end{tabular}

In the dual layer construction, the interlayer space expanded the air pathway, as was analyzed from the contour plots of the simulation. For different virtual models, the differential pressure was compared when the particle was loaded to $10 \sim 12 \mathrm{mg}$ (Table S3), and the air flow phenomenon through the filter construction was analyzed by the contour plots. In Figure S5, the area of green contour (with low pressure drop) was wider in the dual layer construction than in the single layer construction, and the phenomenon was more clearly observed as the layer spacing increased. Several points were analyzed by slicing the middle of the filter (Figure S5), and a similar trend was shown overall.

Table S3. Prediction of pressure drop for virtual constructions with 10-12 mg of challenged mass

\begin{tabular}{|c|c|c|c|c|}
\hline & $\begin{array}{c}\text { m-Fiber } \\
\text { single layer }\end{array}$ & $\begin{array}{c}\text { 2-layer with } \\
\mathbf{1 . 6} \boldsymbol{\mu} \text { m gap }\end{array}$ & $\begin{array}{c}\text { 2-layer with } \\
\mathbf{5 . 0} \boldsymbol{\mu} \text { m gap }\end{array}$ & $\begin{array}{c}\text { 2-layer with } \\
\mathbf{1 0 . 0} \boldsymbol{\mu m} \text { gap }\end{array}$ \\
\hline Particle loading mass (mg) & 11.99 & 10.24 & 11.07 & 11.80 \\
\hline Efficiency (\%) & 99.1 & 99.2 & 99.0 & 99.0 \\
\hline Pressure drop (Pa) & 680.9 & 463.7 & 381.9 & 351.3 \\
\hline
\end{tabular}


(a)

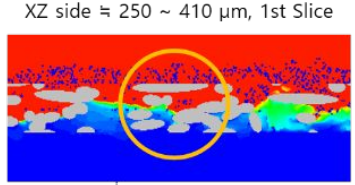

(b)

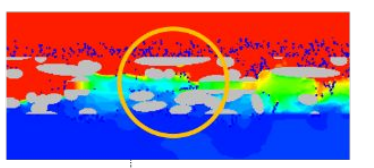

(c)
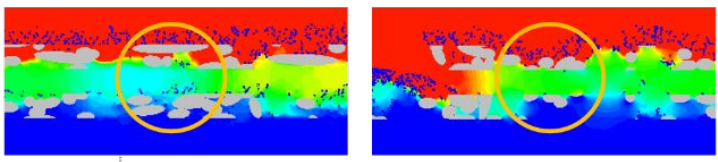

m-Fiber $\times 2$ with $5.0 \mu \mathrm{m}$ gap

(d)

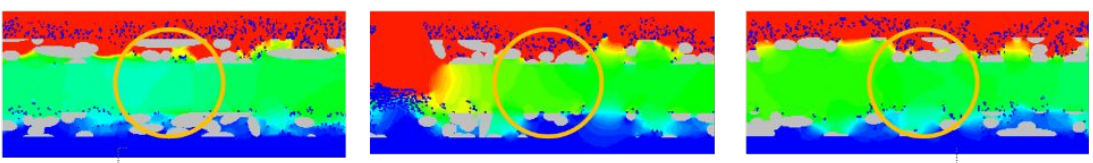

m-Fiber $\times 2$ with $10.0 \mu \mathrm{m}$ gap

(e)

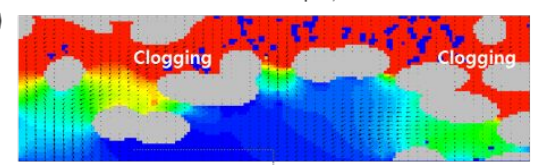

$\mathrm{m}$-Fiber single layer

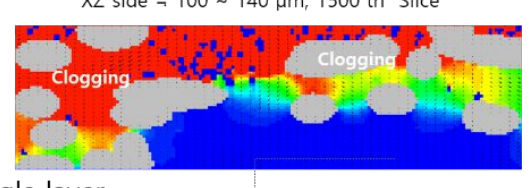

(f)
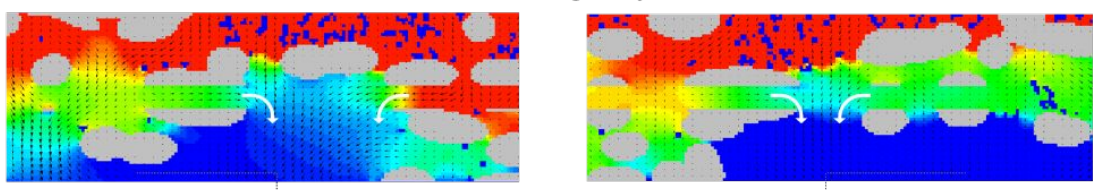

m-Fiber×2 with $1.6 \mu \mathrm{m}$ gap

(g)
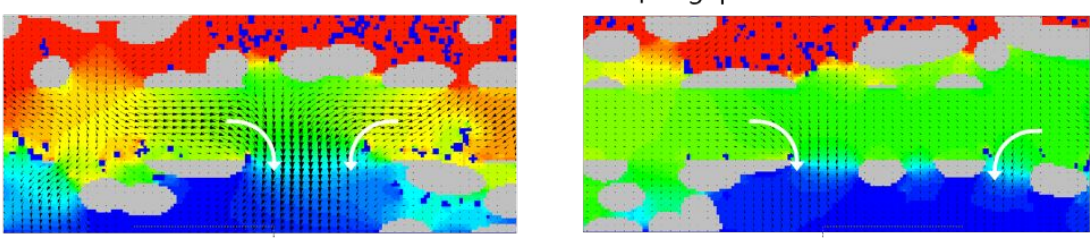

(h)

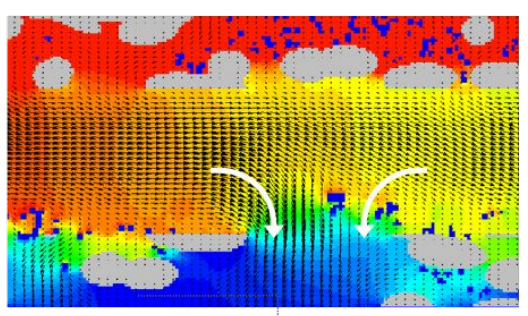

m-Fiber $\times 2$ with $10.0 \mu \mathrm{m}$ gap
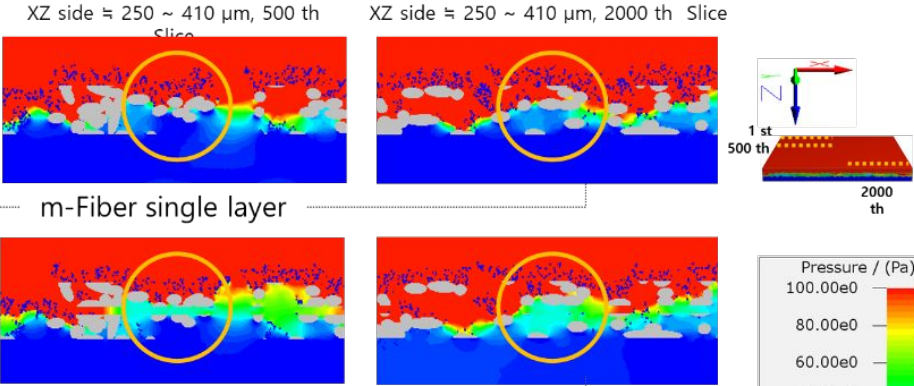

$X Z$ side $こ 250 \sim 410 \mu \mathrm{m}, 2000$ th Slice
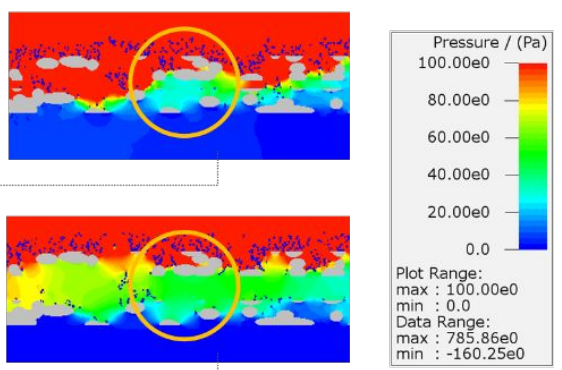

\begin{tabular}{l} 
max : $785.86 \mathrm{e} 0$ \\
$\min :-160.25 \mathrm{e} 0$ \\
\hline
\end{tabular} 


\section{References}

(1) Hung, C. H.; Leung, W. W. F. Filtration of Nano-Aerosol Using Nanofiber Filter under Low Peclet Number and Transitional Flow Regime. Sep. Purif. Technol. 2011, 79, 34-42.

(2) Whitaker, S. Flow in Porous Media I: A Theoretical Derivation of Darcy's Law. Transport Porous Med. 1986, 1, 3-25. 